\section{Kasuistik: Porphyria cutanea tarda}

Typische Hautveränderungen und Verfärbung des Urins weisen auf eine Porphyria cutanea tarda hin.

— in 51-jähriger Mann mit langjährigem Alkoholkonsum, einer chronischen Hepatitis C und Leberzirrhose suchte wegen eines vermehrten periorbitalen Haarwachstums seinen Arzt auf. Im Bereich der lichtexponierten Hautareale fanden sich in Abheilung befindliche, $z$. T. mit Schorf bedeckte Hautläsionen und Narben.

Der Mann schilderte eine gelegentlich auftretende schmerzhafte Blasenbildung im Bereich des Nackens, der Unterarme und der Handrücken (Abb. A). Der Urin des Patienten fluoreszierte im Wood-Licht rosafarben, was für Anwesenheit von Uroporphyrinen sprach (Abb. B: Urin des Patienten (links) im Ultraviolettlicht; normaler Urin (rechts) zum Vergleich). Nachdem sich im Urin des Mannes eine erhöhte Konzentration von Uroporphyrin nachweisen ließ, wurde die Diagnose einer Porphyria cutanea tarda gestellt.

Die Erkrankung beruht auf einer verminderten Aktivität der UroporphyrinDecarboxylase. Die sporadische Form ist häufig mit einer chronischen HCV-Infektion oder einen alkoholischen Leberparenchymschaden assoziiert. Eine faziale
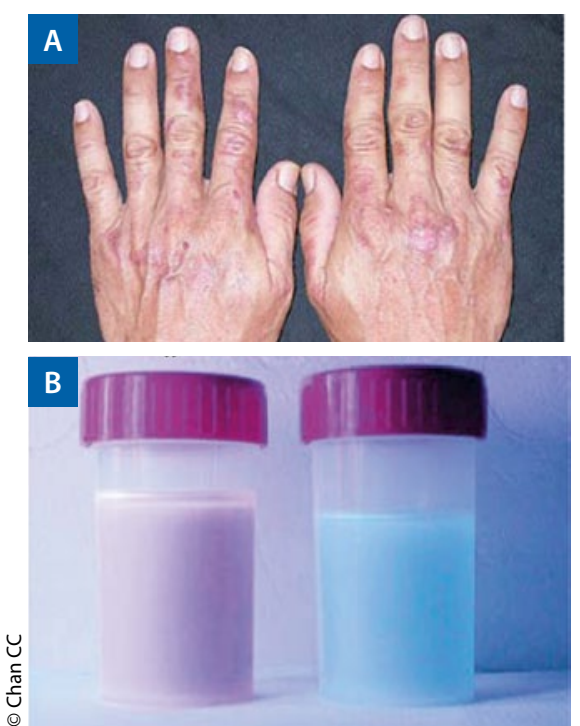

Hautläsionen (A) sowie Urin im UV-Licht (B). Links: rosa gefärbter Patientenurin, rechts: normaler Urin zum Vergleich.
Hypertrichose kommt bei dieser Erkrankung so häufig vor, dass es als fast pathognomonischer Hinweis für das Vorliegen einer Porphyrie gewertet werden kann. Niedrig dosiertes Chloroquin, Lichtschutz der Haut und reduzierter Alkoholkon- sums brachten die Hautläsionen innerhalb von sechs Wochen zur Abheilung.

Prof. Dr. Hermann Füeßl

Chan CC, Lin S-J. Porphyria cutanea tarda. New Engl J Med 2011; 365: 1128 